\title{
Prevalence and associated risk factors of postpartum depression: a cross sectional study
}

REDA GOWEDA ${ }^{1}$

https://orcid.org/0000-0001-5514-1407

Tayseer Metwally2

https://orcid.org/0000-0002-1972-2981

1 Family Medicine Department, Faculty of Medicine, Suez Canal University, Ismailia, Egypt.

2 Family Medicine Department, Faculty of Medicine, Suez University, Suez, Egypt.

Received: 12/28/2019 - Accepted: 03/03/2020

DOI: 10.1590/0101-60830000000242

\begin{abstract}
Background: Postpartum mood disturbance affects up to $85 \%$ of women, with most symptoms of this disturbance being temporary and mild. However up to one in seven women experience a persistent type of depression which is associated with major maternal and neonatal morbidity if it is not managed. Objective: To estimate the prevalence of postpartum depression and to identify the associated risk factors. Methods: A cross sectional study was conducted in randomly selected 3 primary health care centers affiliated to Suez governorate, Egypt. An interviewed questionnaire was used containing potential risk factors for postpartum depression. An Arabic version of the Edinburgh postnatal depression scale (EPDS) was used to screen for postpartum depression symptoms. Results: A total of 237 postpartum mothers were included in the study. 139 (58.6\%) of the mothers completed secondary level of education, 195 (82.3\%) of them were housewives and $181(76.4 \%)$ had cesarean section. The estimated postpartum depression prevalence was $26.6 \%$ and suicidal ideation accounted for 4.6\%. Factors significantly associated with high EPDS scores were bad relationship with the husband, having $>2$ children, an unplanned pregnancy and unhealthy newborn; with P-values of 0.000, 0.004, 0.000, and 0.018, respectively. Discussion: the prevalence of postpartum depression among Egyptian women is considered slightly high with its negative and long term consequences on the mothers and their children, accordingly screening, proper management $\&$ referral to specialist care is highly recommended.
\end{abstract}

Goweda R, Metwally T / Arch Clin Psychiatry. 2020;47(4):106-9

Keywords: Postpartum, depression, risk factors.

\section{Introduction}

Postpartum depression (PPD) is a common health problem that occurs after pregnancy and affects up to $10 \%-15 \%$ of women ${ }^{1,2}$.

PPD is associated with negative effects on the mother-infant relationship and those affected women are more likely to stop breastfeeding early ${ }^{3}$. Children of depressed mothers are more likely to have behavioral problems, failure to thrive, attachment disorder, cognitive delay, emotional and social problems and developmental delay ${ }^{4}$.

Although the cause of postpartum depression is unclear, hormonal, biologic, genetic predisposition, social and psychological factors are considered to be risk factors for all susceptible women ${ }^{5}$.

PPD was classified by the Diagnostic and Statistical Manual of Mental Disorders (DSM-5) as a major depressive disorder that is found during pregnancy or within 4 weeks after delivery ${ }^{6}$. These four weeks may be extended to be within one year postpartum as mentioned by some experts ${ }^{7}$.

The U.S. Preventive Services Task Force (USPSTF) recommends screening postpartum PPD of all women in places with adequate systems to ensure correct diagnosis, effective management and suitable follow-up ${ }^{8}$. There are different screening tests for PPD, the most commonly used validated screening tool for PPD is the 10-item Edinburgh Postnatal Depression Scale (EPDS) 9

Mild to moderate PPD can be treated with psychotherapy as a first line, whereas combination therapy is recommended for moderate to severe depression ${ }^{10}$.

\section{Methods}

This cross sectional prospective study was conducted in randomly selected 3 primary health care centers which is affiliated with Suez governorate, Egypt, between May and October 2019.
After oral consent from all the volunteered mothers, the current study recruited 237 women who attended the child vaccination clinic, family planning clinic, or for follow up at 4th to12th week postpartum and were interviewed face to face by a trained nurse. Females with known mental illness and on treatment or on followup in a psychiatric clinic as well as those who gave birth to children with severe illness such as congenital diseases and malformations were excluded.

An Arabic version of EPDS was used to screen for PPD symptoms. EPDS is the most commonly used validated screening tool for postpartum depression and has a sensitivity of $75 \%$ to $100 \%$ and a specificity of $76 \%$ to $97 \%$ in English-speaking populations ${ }^{11}$. EPDS consists of 10 questions on the women's feelings over the last seven days. Although 10 is the cutoff score in English-speaking populations for probable depression, scores of more than 12 were the optimum cut-off scores for probable depression as validated in Arabic-speaking cultures ${ }^{12-14}$.

Questions were asked for assessment of possible risk factors of PPD such as age, education, occupation, duration of marriage, bond with the husband, number of children, gender of the newborn, smoking status, planning for pregnancy, obstetric complications, fear of labour, labour complications, newborn complications, type of labour, place of labour, type of anesthesia and infant feeding.

SPSS (20.0) was used for data analysis of this study. For quantitative data, t-test was used. Chi-square test (Fisher's exact test) was used to examine the relation between qualitative variables and $\mathrm{P}<0.05$ was considered statistically significant.

\section{Results}

A total of 237 postpartum women who completed the sociodemographic and obstetric variables section and the EPDS questionnaire were included in our study. The mean age was 27.9 years $(\mathrm{SD}=5.9)$, ranging from 17 to 45 years. $139(58.6 \%)$, or more 
than half of the mothers completed either elementary or secondary level of education, 34 (14.3\%) achieved higher education, 56 (23.6\%) could read and write, and only 8 (3.4\%) were illiterate. $195(82.3 \%)$, the majority of the mothers were housewives, and 148 (62.4\%) of the mothers fell under the category of passive second-hand smokers with none being an active smoker. 159 (67.1\%) of the mothers had $\leq 2$ children. Regarding the sex of children in the family 80 (33.8\%) of the mothers had boys only, 55 (23.2\%) had girls only, 102 (43.0\%) had both gender. Few of the mothers reported that their pregnancies were unplanned pregnancies 31 (13.1\%). Fifty six (23.6\%) of the mothers reported health problems during pregnancy. Out of 237 women, 181 (76.4\%) had cesarean section and $56(23.6 \%)$ had normal vaginal delivery. The estimated PPD prevalence in our study was $26.6 \%$ and suicidal ideation accounted for $4.6 \%$ (Table 1 ).

Young mothers were less likely to have depressive symptoms. Mean \pm SD age of depressed women was $30.5 \pm 6.5$ while non depressed mothers were $26.9 \pm 5.5$ with a p value of 0.000 . Years of marriage had no significant effect on EPDS scores; depressed mothers were married for 6.61 years $( \pm 5.52)$ whereas non-depressed were married $5.28( \pm 4.44)$ with a p value of 0.057 (Table 2).

Factors significantly associated with high EPDS scores were a poor relationship with the husband, having more than 2 children, unplanned pregnancies and unhealthy newborns, with P-values of $0.000,0.004,0.000$, and 0.018 , respectively. Factors not significantly influencing EPDS scores were educational level, maternal occupation, infant gender, smoking status, obstetric health problems, type of labour, whether received anesthesia, fear of labour, and infant feeding, with p-values of $0.517,0.275,0.573,0.310,0.077,0.836,0.067,0.094$, 0.335 and 0.602 , respectively (Table 3 ).

\section{Discussion}

Prevalence of PPD has a very wide range worldwide. This was clearly shown in a review by Siti et al. who found that the prevalence of PPD ranged from 4.0\%-63.9\% with Japan and America recording the lowest and highest rates of PPD respectively ${ }^{15}$. This finding is consistent with an earlier finding of a review of 143 studies across 40 countries that identified that the prevalence of PPD ranged from $0-60 \%{ }^{16}$.

The findings of the current study demonstrated the estimated prevalence of PPD is $26.6 \%$ which is higher than figures reported by other studies in western countries as in Canada and United Kingdom were $10 \%-15 \%$ and $12.8 \%$ respectively 17,18 . A Meta analysis by O'Hara \& Swain included 59 studies from North America, Europe, and Australasia scored an overall prevalence rate of PPD of $13 \%{ }^{19}$.

On the other hand most of studies conducted in Arab countries recorded a higher prevalence of PPD than in more developed countries. The estimated PPD prevalence in Lebanon is $21 \%{ }^{20}$, United Arab Emirates (UAE) 22\% ${ }^{21}$, Tunisia 19.2\% ${ }^{22}$, Jordan $22 \%{ }^{23}$, Saudi Arabia $33.2 \%{ }^{24}$, Bahrain $37.1 \%{ }^{25}$, and Oman $10 \%{ }^{14}$. The reasons for the wide range of prevalence may be explained by many reasons such as cross-cultural differences ${ }^{26}$, the way in which women understand and interpret items in the EPDS, postpartum time of screening and cutoff scores for screening.

In the current study older women were at a higher risk of depression than younger women, which is similar to previous studies stating advanced and very young maternal age are risk factors for $\mathrm{PPD}^{24,27,28}$. This finding varies from results reported in many previous studies ${ }^{29}$, such as by Stowe et al. showing mothers between the ages of 15 and 19 years had more risk for PPD ${ }^{30}$.

Table 2. Effect of maternal age and marriage duration on EPDS scores

\begin{tabular}{|c|c|c|c|c|c|}
\hline & & \multirow[t]{2}{*}{ Mean \pm SD } & \multicolumn{2}{|c|}{ 95\% Confidence Interval } & \multirow[t]{2}{*}{$P$ value } \\
\hline & & & Lower & Upper & \\
\hline \multirow[t]{2}{*}{ Maternal Age } & Depressed & $30.53 \pm 6.46$ & \multirow[t]{2}{*}{1.89245} & \multirow[t]{2}{*}{5.22140} & \multirow[t]{2}{*}{0.000} \\
\hline & Not depressed & $26.98 \pm 5.46$ & & & \\
\hline \multirow[t]{2}{*}{ Duration of Marriage } & Depressed & $6.61 \pm 5.52$ & \multirow[t]{2}{*}{-.04218} & \multirow[t]{2}{*}{2.71131} & \multirow[t]{2}{*}{0.057} \\
\hline & Not depressed & $5.28 \pm 4.44$ & & & \\
\hline
\end{tabular}

\begin{tabular}{|l|l|c|c|c|c|}
\hline \multicolumn{2}{|l|}{} & Mean \pm SD & \multicolumn{2}{|c|}{$95 \%$ Confidence Interval } & P value \\
\cline { 2 - 5 } \multicolumn{2}{|l|}{ Maternal Age } & Lepressed & $30.53 \pm 6.46$ & 1.89245 & 5.22140 \\
\cline { 2 - 5 } & Not depressed & $26.98 \pm 5.46$ & & 0.000 \\
\hline Duration of Marriage & Depressed & $6.61 \pm 5.52$ & -.04218 & 2.71131 \\
\cline { 2 - 5 } & Not depressed & $5.28 \pm 4.44$ & & 0.057 \\
\hline
\end{tabular}

Table 1. General characteristics of the participants

\begin{tabular}{|c|c|c|}
\hline & & $\mathrm{N}(\%)$ \\
\hline \multirow[t]{3}{*}{ Marital status } & Married & $231(97.5)$ \\
\hline & Widowed & $4(1.7)$ \\
\hline & Divorced & $2(0.8)$ \\
\hline \multirow[t]{2}{*}{ Spousal Relationship } & Good quality & $226(95.4)$ \\
\hline & Poor quality & $11(4.6)$ \\
\hline \multirow[t]{4}{*}{ Educational level } & Higher education & $34(14.3)$ \\
\hline & Secondary schooling & $139(58.6)$ \\
\hline & Can read and write & 56 (23.6) \\
\hline & Illiterate & $8(3.4)$ \\
\hline \multirow[t]{3}{*}{ Occupation } & House-wife & $195(82.3)$ \\
\hline & Working & $42(17.7)$ \\
\hline & Neither & 89 (37.6) \\
\hline \multirow[t]{2}{*}{ Number of children } & $\leq 2$ & $159(67.1)$ \\
\hline & $>2$ & $78(32.9)$ \\
\hline \multirow[t]{3}{*}{ Sex of children } & Males & 80 (33.8) \\
\hline & Females & $55(23.2)$ \\
\hline & Both & $102(43.0)$ \\
\hline \multirow[t]{2}{*}{ Passive smoking } & Yes & $148(62.4)$ \\
\hline & No & 89 (37.6) \\
\hline \multirow[t]{2}{*}{ Planned pregnancy } & Yes & $206(86.9)$ \\
\hline & No & $31(13.1)$ \\
\hline \multirow{2}{*}{$\begin{array}{l}\text { Obstetric health } \\
\text { problems }\end{array}$} & Yes & $56(23.6)$ \\
\hline & No & $181(76.4)$ \\
\hline \multirow[t]{3}{*}{ Place of labour } & Hospital & $206(86.9)$ \\
\hline & Home & $5(2.1)$ \\
\hline & Clinic/Medical center & $26(11.0)$ \\
\hline \multirow[t]{2}{*}{ Type of labour } & Normal vaginal & $56(23.6 \%)$ \\
\hline & Cesarean Section & $181(76.4 \%)$ \\
\hline \multirow[t]{2}{*}{ Received anesthesia } & Yes & $114(48.1)$ \\
\hline & No & $123(51.9)$ \\
\hline \multirow[t]{2}{*}{ Fear of labour } & Yes & 212 (89.5) \\
\hline & No & $7(3.0)$ \\
\hline \multirow[t]{2}{*}{ Labour complications } & Yes & $23(9.7)$ \\
\hline & No & $214(90.3)$ \\
\hline \multirow[t]{2}{*}{ Newborn's sex } & Male & $112(47.3)$ \\
\hline & Female & $125(52.7)$ \\
\hline \multirow{2}{*}{$\begin{array}{l}\text { Newborn's health } \\
\text { problems }\end{array}$} & Yes & $35(14.8)$ \\
\hline & No & 202 (85.2) \\
\hline \multirow{3}{*}{$\begin{array}{l}\text { Feeding of the } \\
\text { Newborn }\end{array}$} & Breast feeding & $179(75.5)$ \\
\hline & Artificial feeding & $26(11)$ \\
\hline & Both & 32 (13.5) \\
\hline \multirow{2}{*}{$\begin{array}{l}\text { Postpartum } \\
\text { depression }\end{array}$} & Depressed (EPDS scores $\geq 12$ ) & $63(26.6)$ \\
\hline & Not depressed (EPDS scores $\geq 12$ ) & $174(73.4)$ \\
\hline \multirow[t]{2}{*}{ Suicidal ideation } & Yes & $11(4.6)$ \\
\hline & No & $226(95.4)$ \\
\hline
\end{tabular}


Table 3. Evaluation of various factors affecting EPDS scores

\begin{tabular}{|c|c|c|c|c|}
\hline & & \multicolumn{2}{|c|}{ Depression } & \multirow[t]{2}{*}{ Pvalue } \\
\hline & & $\begin{array}{c}\text { Depressed } \\
(\mathrm{N}=63)\end{array}$ & Not depressed $(\mathrm{N}=174)$ & \\
\hline \multirow[t]{4}{*}{ Education } & Highly educated & $12(19.0 \%)$ & $22(12.6 \%)$ & \multirow[t]{4}{*}{0.517} \\
\hline & Secondary schooling & $35(55.6 \%)$ & $104(59.8 \%)$ & \\
\hline & Read \& write & $13(20.6 \%)$ & $43(24.7 \%)$ & \\
\hline & Illiterate & $3(4.8 \%)$ & $5(2.9 \%)$ & \\
\hline \multirow[t]{2}{*}{ Occupation } & House wife & $49(77.8 \%)$ & $146(83.9 \%)$ & \multirow[t]{2}{*}{0.275} \\
\hline & working & $14(22.2 \%)$ & $28(16.1 \%)$ & \\
\hline \multirow[t]{3}{*}{ Marital status } & Married & $58(92.1 \%)$ & $173(99.4 \%)$ & \multirow[t]{3}{*}{0.005} \\
\hline & Divorced & $3(4.8 \%)$ & $1(0.6 \%)$ & \\
\hline & widow & $2(3.2 \%)$ & $0(0 \%)$ & \\
\hline \multirow{2}{*}{ Spousal Relationship } & Good & $53(84.1 \%)$ & $173(99.4 \%)$ & \multirow[t]{2}{*}{0.000} \\
\hline & Bad & $10(15.9 \%)$ & $1(0.6 \%)$ & \\
\hline \multirow[t]{2}{*}{ Number of children } & $\leq 2$ & $33(52.4 \%)$ & $126(72.4 \%)$ & \multirow[t]{2}{*}{0.004} \\
\hline & $>2$ & $30(47.6 \%)$ & $48(27.6 \%)$ & \\
\hline \multirow[t]{3}{*}{ Sex of children } & Males & $18(28.6 \%)$ & $62(35.6 \%)$ & \multirow[t]{3}{*}{0.573} \\
\hline & Females & $15(23.8 \%)$ & $40(23.0 \%)$ & \\
\hline & Both & $30(47.6 \%)$ & $72(41.4 \%)$ & \\
\hline \multirow[t]{2}{*}{ Passive smoking } & Yes & $36(57.1 \%)$ & $112(64.4 \%)$ & \multirow[t]{2}{*}{0.310} \\
\hline & No & $27(42.9 \%)$ & $62(35.6 \%)$ & \\
\hline \multirow[t]{2}{*}{ Planned pregnancy } & Yes & $42(66.7 \%)$ & $164(94.3 \%)$ & \multirow[t]{2}{*}{0.000} \\
\hline & No & $21(33.3 \%)$ & $10(5.7 \%)$ & \\
\hline \multirow[t]{2}{*}{ Obstetric health problems } & Yes & $20(31.7 \%)$ & $36(20.7 \%)$ & \multirow[t]{2}{*}{0.077} \\
\hline & No & $43(68.3 \%)$ & $138(79.3 \%)$ & \\
\hline \multirow[t]{3}{*}{ Place of Labour } & Hospital & $54(85.7 \%)$ & $152(87.4 \%)$ & \multirow[t]{3}{*}{0.836} \\
\hline & Home & $1(1.6 \%)$ & $4(2.3 \%)$ & \\
\hline & Clinic/Medical center & $8(12.7 \%)$ & $18(10.3 \%)$ & \\
\hline \multirow[t]{2}{*}{ Type of Labour } & Normal vaginal & $30(47.6 \%)$ & $106(60.9 \%)$ & \multirow[t]{2}{*}{0.067} \\
\hline & C.S. & $33(52.4 \%)$ & $68(39.1 \%)$ & \\
\hline \multirow[t]{2}{*}{ Received anesthesia } & Yes & $36(57.1 \%)$ & $78(44.8 \%)$ & \multirow[t]{2}{*}{0.094} \\
\hline & No & $27(42.9 \%)$ & $96(55.2 \%)$ & \\
\hline Fear of labour & Yes & $56(94.9 \%)$ & $156(97.5 \%)$ & 0.335 \\
\hline & No & $3(5.1 \%)$ & $4(2.5 \%)$ & \\
\hline Labour complications & Yes & $12(19.0 \%)$ & $11(6.3 \%)$ & 0.003 \\
\hline & No & $51(81.0 \%)$ & $163(93.7 \%)$ & \\
\hline Newborn's sex & Male & $28(44.4 \%)$ & $84(48.3 \%)$ & 0.602 \\
\hline & Female & $35(55.6 \%)$ & $90(51.7 \%)$ & \\
\hline Newborn's health problems & Yes & $15(23.8 \%)$ & $20(11.5 \%)$ & 0.018 \\
\hline & No & $48(76.2 \%)$ & $154(88.5 \%)$ & \\
\hline Feeding of the Newborn & Breast & $42(66.7 \%)$ & $137(78.7 \%)$ & 0.157 \\
\hline & Artificial & $9(14.3 \%)$ & $17(9.8 \%)$ & \\
\hline & Both & $12(19 \%)$ & $20(11.5 \%)$ & \\
\hline
\end{tabular}

Conflict and poor spousal relationship increased the risk of depression which agrees with findings by Chan et al. ${ }^{31}$. Additionally previous research has illustrated a positive association between informal structural social support, essentially that given by a partner ${ }^{32}$.

This study has shown that mothers having more than two children are likely to be more depressed than being a first-time mother or having two children. This is in agreement with low-income countries such as Nepal and Pakistan ${ }^{33,34}$. Multi-parity increases family stress and the risk of PPD due to the physical and financial burden associated with childcare. In the UAE, multi-parity is a protective factor for PPD 21 .

The current study showed that there is a significant relation between depression and marital status as divorced or widowed women were more likely to be depressed which is in disagreement with a study by Watson $\mathrm{JP}^{35}$ who found that there is no correlation between PPD and marital status
Beside previous factors increasing risk of depression, unplanned pregnancy was found to be one of the significant factors in the current study to increase EPDS scores.

In the current study it was found that there is no significant relationship between method of delivery and PPD which is consistent with the results of Johnstone et al. who reported a non significant trend between postpartum depression and caesarean section ${ }^{36}$. Additionally Warner et al. ${ }^{37}$ found no significant association between elective or emergency caesarean section and subsequent postpartum depression while Fisher and colleagues reported that cesarean section was associated with increased risk of PPD ${ }^{38}$.

This study discovered the risk of PPD is nearly equal among housewives compared to those who were working away from their homes. However, in contrast to our finding, other studies have reported an excess risk of PPD among housewives ${ }^{39-40}$. Our study did not find maternal level of education as a risk factor for PPD, which is consistent with the finding of another study ${ }^{41}$, but differs 
from some other reports ${ }^{42}$. No differences were observed regarding risk of PPD with regard to the sex of the child, which is in line with some other studies ${ }^{43}$. This study has shown that there is no significant association between EPDS scores and whether the patient had obstetric complications, the smoking status, or whether the infant was breast fed or formula fed.

Lastly, we can conclude relatively older females, a fragile spousal relationship, multi-parity, and unplanned pregnancies were associated with higher risk of PPD.

\section{Conflict of interests}

There are no conflicts of interest.

\section{Financial support and sponsorship}

None.

\section{References}

1. Gavin NI, Gaynes BN, Lohr KN, Meltzer-Brody S, Gartlehner G, Swinson T. Perinatal depression: a systematic review of prevalence and incidence. Obstet Gynecol. 2005;106(5 Pt 1):1071-83.

2. USPSTF. Screening for depression in adults: U.S. preventive services task force recommendation statement. Ann Intern Med. 2009;151(11):784-92.

3. Brown A, Rance J, Bennett P. Understanding the relationship between breastfeeding and postnatal depression: the role of pain and physical difficulties. J Adv Nurs. 2016;72(2):273-82.

4. Murray L, Cooper PJ. Postpartum depression and child development. Psychol Med. 1997;27(2):253-60.

5. Lancaster CA, Gold KJ, Flynn HA, Yoo H, Marcus SM, Davis MM. Risk factors for depressive symptoms during pregnancy: a systematic review. Am J Obstet Gynecol. 2010;202(1):5-14.

6. Gaynes BN, Gavin N, Meltzer-Brody S, Lohr KN, Swinson T, Gartlehner G, et al. Perinatal depression: prevalence, screening accuracy, and screening outcomes. Evidence Report/Technology Assessment no 119. Rockville, Md.: Agency for Healthcare Research and Quality; 2005. Available from: http://archive.ahrq.gov/downloads/pub/evidence/pdf/ peridepr/peridep.pdf. Accessed on: Jan 15, 2016.

7. Siu AL, Bibbins-Domingo K, Grossman DC, Baumann LC, Davidson KW, Ebell M, et al. Screening for depression in adults: US preventive services task force recommendation statement. JAMA. 2016;315(4):380-7.

8. American Psychiatric Association. Diagnostic and Statistical Manual of Mental Disorders. 5th ed. Washington, DC: American Psychiatric Association; 2013.

9. Cox JL, Holden JM, Sagovsky R. Detection of postnatal depression. Development of the 10-item Edinburgh Postnatal Depression Scale. Br J Psychiatry. 1987;150:782-6.

10. Yonkers KA, Vigod S, Ross LE. Diagnosis, pathophysiology, and management of mood disorders in pregnant and postpartum women. Obstet Gynecol. 2011;117(4):961-77.

11. Zubaran C, Schumacher M, Roxo MR, Foresti K. Screening tools for postpartum depression: validity and cultural dimensions. Afr J Psychiatry (Johannesbg). 2010;13(5):357-65.

12. Agoub M, Moussaoui D, Battas O. Prevalence of postpartum depression in a Moroccan sample. Arch Womens Ment Health. 2005;8(1):37-43.

13. Ghubash R, Abou-Saleh MT. Postpartum psychiatric illness in Arab culture: prevalence and psychosocial correlates. Br J Psychiatry. 1997;171(1):65-8.

14. Al Hinai FI, Al Hinai SS. Prospective Study on Prevalence and Risk Factors of Postpartum Depression in Al-Dakhliya Governorate in Oman. Oman Med J. 2014;29(3):198-202.

15. Arifin SRM, Cheyne H, Maxwell M. Review of the prevalence of postnatal depression across cultures. AIMS Public Health. 2018;5(3):260-95.

16. Halbreich U, Karkun S. Cross-cultural and social diversity of prevalence of PPD and depressive symptoms. J Affect Disord. 2006;91:97-111.

17. Leitch S. Postpartum Depression: A Review of the Literature. St. Thomas, Ontario: Elgin-St. Thomas Health Unit; 2002.

18. Halbreich U, Karkun S. Cross-cultural and social diversity of prevalence of postpartum depression and depressive symptoms. J Affect Disord. 2006;91:97-111.
19. O'Hara MW, Swain AM. Rates and risk of postpartum depression-a meta-analysis. Int Rev Psychiatry. 1996;8:37-54.

20. Chaaya M, Campbell OM, El Kak F, Shaar D, Harb H, Kaddour A. Postpartum depression: prevalence and determinants in Lebanon. Arch Womens Ment Health. 2002;5(2):65-72.

21. Katherine G, Broome H, Mirabella J. Postnatal depression among mothers in the United Arab Emirates: socio-cultural and physical factors. Psychol Health Med. 2006;11(4):425-31.

22. Masmoudi J, Tabelsi S, Charfeddine F, Ben Ayed B, Guermazzi M, Jaoua A. [Study of the prevalence of postpartum depression among 213 Tunisian parturients]. Gynecol Obstet Fertil 2008;36(7-8):782-7.

23. Mohammad KI, Gamble J, Creedy DK. Prevalence and factors associated with the development of antenatal and postnatal depression among Jordanian women. Midwifery. 2011;27(6):e238-45.

24. Alharbi AA, Abdulghani HM. Risk factors associated with postpartum depression in the Saudi population. Neuropsychiatr Dis Treat. 2014:10:311-6.

25. Al Dallal FH, Grant IN. Postnatal depression among Bahraini women: prevalence of symptoms and psychosocial risk factors. East Mediterr Health J. 2012;18(5):439-45.

26. Halbreich U, Karkun S. Cross-cultural and social diversity of prevalence of postpartum depression and depressive symptoms. J Affect Disord. 2006;91(2-3):97-111.

27. Bjerke SE, Vangen S, Nordhagen R, Yiterdahl T, Magnus P, Stray Pedersen B. Postpartum depression among Pakistani women in Norway: prevalence and risk factors. J Matern Fetal Neonatal Med. 2008;21(12):889-94.

28. Wolff A, De-Andraca I, Lozoff B. Maternal depression in three Latin American samples. Soc Psychiatry Psychiatr Epidemiol. 2002;37(4):169-76.

29. Reid V, Meadows-Oliver M. Postpartum depression in adolescent mothers: an integrative review of the literature. J Pediatr Health Care. 2007;21(5):289-98.

30. Stowe ZN, Nemeroff CB. Women at risk for postpartum-onset major depression. Am J Obst Gynecol. 1995;173:639-45.

31. Chan SW, Levy V, Chung TK, Lee D. A qualitative study of the experiences of a group of Hong Kong Chinese women diagnosed with postnatal depression. J Adv Nurs. 2002;39(6):571-9.

32. Dennis CL, Ross L. Women's perceptions of partner support and conflict in the development of postpartum depressive symptoms. J Adv Nurs. 2006;56(6):588-99.

33. Ho-Yen SD, Bondevik GT, Eberhard-Gran M, Bjorvatn B. Factors associated with depressive symptoms among postnatal women in Nepal. Acta Obstet Gynecol Scand. 2007;86(3):291-7.

34. Rahman A, Creed F. Outcome of prenatal depression and risk factors associated with persistence in the first postnatal year: Prospective study from Rawalpindi, Pakistan. J Affect Disord. 2007;100(1-3):115-21.

35. Watson JP, Elliot SA, Rugg AJ, Brough DL. Psychiatric disorder in pregnancy and the first postnatal year. Br J Psychiatry. 1984;144:453-62.

36. Johnstone SJ, Boyce PM, Hickey AR, Morris-Yatees AD, Harris MG. Obstetric risk factors for postnatal depression in urban and rural community samples. Aust N Z J Psychiatry. 2001;35:69-74.

37. Warner R, Appleby L, Whitton A, Faragher B. Demographic and obstetric risk factors for postnatal psychiatric morbidity. Br J Psychiatry. 1996;168:607-11.

38. Fisher J, Astbury J, Smith A. Adverse psychological impact of operative obstetric interventions: a prospective longitudinal study. Aust N Z J Psychiatry. 1997;31:728-38.

39. Lee DT, Yip AS, Leung TY, Chung TK. Identifying women at risk of postnatal depression: prospective longitudinal study. Hong Kong Med J. 2000;6(4):349-54.

40. Goker A, Yanikkerem E, Demet MM, Dikayak S, Yildirim Y, Koyuncu FM. Postpartum depression: is mode of delivery a risk factor? ISRN Obstet Gynecol. 2012;2012:616759.

41. Saleh El-S, El-Bahei W, El-Hadidy MA, Zayed A. Predictors of postpartum depression in a sample of Egyptian women. Neuro Psychiatr Dis Treat. 2013;9:15-24.

42. Rahman A, Iqbal Z, Harrington R. Life events, social support, and depression in childbirth: perspectives from a rural community in the developing world. Psychol Med. 2003;33(7):1161-7.

43. Sylvén SM, Papadopoulos FC, Mpazakidis V, Ekselius L, Sundström-Poromaa I, Skalkidou A. Newborn gender as a predictor of postpartum mood disturbances in a sample of Swedish women. Arch Womens Ment Health. 2011;14(3):195-201. 